\title{
Measuring Emotional Intelligence of Secondary School Students in Relation to Gender and Residence: an Empirical Study
}

\author{
Dhiman Kar ${ }^{1}$, Birbal Saha ${ }^{1, *}$, Bhim Chandra Mondal ${ }^{2}$ \\ ${ }^{1}$ Department of Education, Sidho-Kanho-Birsha University, Purulia, West Bengal, India \\ ${ }^{2}$ Sponsored Teachers' Training College, Purulia, West Bengal, India \\ *Corresponding author: birbalsaha@gmail.com
}

Received March 06, 2014; Revised March 14, 2014; Accepted March 25, 2014

\begin{abstract}
In the age of zero-tolerance, virtual reality and ultramodern technology, the studying of human emotion has become so urgent that it demands our serious concentration for its scientific measurement. This present paper will make a thorough investigation in understanding the deeper interrelations between human emotion and intelligence. This article will also focus the emotional intelligence of secondary school students in relation to their gender and residential background. Emotional intelligence has been measured by applying Mondal's Emotional Intelligence Inventory (MEII) consisted with 100 items. 235 samples were randomly selected from the district of Purulia, WB, India. ANOVA and 't ' test has been applied for the interpretation of the findings. The results reveal that residential place plays a significant role for the enlargement of emotional development whereas gender does not affect the level of Emotional Intelligence.
\end{abstract}

Keywords: emotional intelligence, boys, girls, residential back ground, ANOVA, ' $t$ '-test

Cite This Article: Dhiman Kar, Birbal Saha, and Bhim Chandra Mondal, "Measuring Emotional Intelligence of Secondary School Students in Relation to Gender and Residence: an Empirical Study." American Journal of Educational Research, vol. 2, no. 4 (2014): 193-196. doi: 10.12691/education-2-4-3.

\section{Introduction}

If one is asked about the latest invention of human psychology, undoubtedly the answer is measuring of emotional intelligence of a human being by following a reliable scale. Emotional intelligence has now become the point of general interest for public, practitioners and researchers in the school, colleges and universities. It is believed that emotional and social competences are as important as traditional dimensions of intellectual ability and personality [1,2]. A person's emotional intelligence helps much in all spheres of life through its various constituents or components namely knowledge of one's emotions and handling relationships. Emotional intelligence is another layer of human mind which is constructive enough in exploring human intelligence by processing a scientific method. Such systematic understanding of human emotion to measure human intelligence will prove much beneficial in uplifting common success rate of contemporary education and its system. Thus, emotional intelligence essentially reflects our ability to deal successfully with other people and with our own feelings. Curiosity of the good academics needs to study such emotional intelligence to get the meaningful echoes of human heart.

In the last two decades of $20^{\text {th }}$ and $21^{\text {st }}$ century, Emotional Intelligence has been variously defined from multitudinous angles. Emotional intelligence was described formally by Salovey and Mayer (1990) according to whom "the ability to monitor one's own and others' feelings and emotions, to discriminate among them and to use this information to guide one's thinking and actions [3].”According to Daniel Goleman (1995), "Emotional intelligence is the capacity for recognizing our own feelings and those of others, for motivating ourselves, and for managing emotions well in us and in our relationships [1].” Goleman (2002) in his research has identified a set of competencies that differentiate children with emotional intelligence. The competencies fall into four clusters such as Self Awareness (understanding of own emotions, powers, weaknesses, needs and awareness of self-existence), Self Management (managing own emotional behavior), Social Awareness (ability to understand emotions and needs of others and thus putting oneself into others' shoes) and Relationship Management (ability to establish relationships with other individuals and to ensure sustainability of such relationships, creating and managing a team) [4].

Emotional intelligence is a scientific human endeavour to bridge between two different human conditions of one human body, originating from head and heart respectively. Such collaboration of meaningful human emotions plays a pivotal role in deciding human achievement. Emotional intelligence is a phase that incorporates the intricate aspects of both emotion and intelligence. Emotions rule the heart while intelligence reigns supreme in the brain. 
The twice-qualities are inseparable and they exercise tremendous influence in the lives of individuals. Emotional intelligence can make a unique contribution to a better understanding of people and also use their potential to success [5]. The intellectual behaviour of a person is meaningfully decided by the emotional state of mind.

\section{Literature Review}

It is almost a proverbial truth that women have no greater and larger emotional intelligence than men that claims serious scientific and systematic understanding. Why men are more emotionally intelligent than women? What has decided such greater and larger level of emotional intelligence in men? What are the chief operating factors behind all these? Is there any way out to understand and swallow all these? An analysis of emotional intelligence was found in thousands of men and women which showed that women, on average, are more aware of their emotions, show more empathy, and are more adept interpersonally. Since females tend to be more emotional and intimate in relationships as compared to males, so their emotional intelligence ought to be higher than that of males [6,7]. Men, on the other hand, are more self-confident, optimistic, and adaptable. It was found that men are also able to handle stress better than women. In general, however, far more similarities exist than differences. Some men are empathetic as the most interpersonally sensible women are, while some women are just as able to withstand stress as the most emotionally resilient men.

Studies of emotional intelligence have shown its relevance to many aspects of life and the role it plays in the interactions and adjustments in daily life. Punia and Sangwan (2011) [8] found that girls are more emotionally intelligent than boys where as Chu (2002) [9] revealed that Boys are more emotionally intelligent. Thilagavathy (2013) [10] found that there is no significance difference of emotional intelligence between urban and rural teacher but significance difference exist between male and female teacher where as Gangal and Singh (2012) [11] established that male and female, rural and urban teacher trainee do not differ significantly in reference to their emotional intelligence. Thus, it is seen that the studies conducted come up with different results and it is becoming difficult to make generalizations. When we consider the number of factors having impact on the levels of emotional intelligence and their form of impact, it is clear that conducting several studies on this field, at different places by using different variables is necessary.

Emotional intelligence of a person largely depends on the agents which are very influential for the successful and effective socialization of a person. Emotional intelligence has been highly predisposed by culture of the society in which the individual belongs [12]. In the modern world, education is getting widened and there is a cut-throat competition among students to excel. In age the rapid expansion of education and unhealthy competitions among the learners the systematic studying of emotional intelligence becomes relevant and necessary as well. Students feel complicated to organize their emotions in order to face various situations in school life. It is imperative to manage the stress and strain to keep pace with the demands of the world.

In view of the above, the Investigators tried to conduct a study to determine the extent of relationship between emotional intelligence, gender and residential background of secondary school students, so that efforts can be made to develop a strategic plan for recommending to the school to improve the emotional intelligence of children and hence, helping the adolescents to make this period a more adjusting and enjoyable time leading to success in adolescents life.

\section{Objectives}

The study was conducted with the following objectives:

1. To compare emotional intelligence between rural and urban students at secondary level.

2. To compare emotional intelligence between boys and girls students at secondary level.

3. To study the interaction effect between gender and residential background.

\section{Hypotheses}

$\mathrm{H}_{1}$ : There is no significance difference between urban and rural students regarding their emotional intelligence.

$\mathrm{H}_{2}$ : There is no significance difference between boys and girls regarding their emotional intelligence (EI).

$\mathrm{H}_{3}$ : There is no significant interaction effect of emotional intelligence between gender and residential background.

\section{Population}

All the $\mathrm{XI}^{\text {th }}$ standard students (approx 5000) of higher secondary level of Purulia district, West Bengal, are the population of this research.

\section{Sample}

Sample of 235 higher secondary school students were randomly selected from 8 higher secondary schools out of which 4 from urban area and 4 from rural area of Purulia district, West Bengal. The sample distribution is given in Table 1:

Table 1. Sample profile

\begin{tabular}{|c|c|c|c|}
\hline & Urban & Rural & Total \\
\hline Boys & 51 & 50 & 101 \\
\hline Girls & 58 & 76 & 134 \\
\hline Total & 109 & 126 & 235 \\
\hline
\end{tabular}

\section{Tools}

Emotional Intelligence Inventory (EII) as developed by Mondal (2014) is used for the present study. The scale is based on four dimensions viz. self awareness, self management, social awareness and relationship management as per Goleman's view (2002) [4]. This is a three point Likert type scale consists of 100 items by taking 25 items from each dimensions. The reliability of 
the scale was 0.82 by split half method and internal consistency was 0.90 as measured by Cronbach method. A reliability coefficient greater than 0.70 confirms that the scale used in the study is reliable [13]. The questionnaire forms also include questions covering demographic characteristics of students such as age, residential background.

\section{Procedure}

As indicated earlier, secondary school students were randomly sampled from different residential background of Purulia district, WB. It is always important to establish good "rapport" with the subjects, whether tested individually or in groups. 235 samples comprising of 126 rural and 109 urban students were given Emotional Intelligence Inventory (EII). All subjects were tested individually. The testing time took approximately 45 minutes to one hour for each subject. After the collection of data the responses of the participants were scored and after the final scoring the scores were analyzed in form of appropriate statistical tests.

Table 2. Determination of ' $t$ ' values

\begin{tabular}{|c|c|c|c|c|c|c|}
\hline Pair of comparison & $\mathrm{N}$ & Mean & SD & Mean Difference & $\begin{array}{c}\text { Std error mean } \\
\text { diff }\end{array}$ & 't' value \\
\hline Boys & 101 & 115.7 & 18.1 & \multirow{2}{*}{0.94} & \multirow{2}{*}{2.39} & \multirow{2}{*}{$0.394^{\#}$} \\
\hline Girls & 134 & 116.6 & 19.6 & & & \\
\hline Rural & 126 & 113.3 & 18.6 & \multirow{2}{*}{6.67} & \multirow{2}{*}{2.45} & \multirow{2}{*}{$2.75^{* *}$} \\
\hline Urban & 109 & 119.5 & 21.8 & & & \\
\hline Rural Boys & 50 & 115.2 & 21.9 & \multirow{2}{*}{1.56} & \multirow{2}{*}{3.48} & \multirow{2}{*}{$0.447^{\#}$} \\
\hline Urban Boys & 51 & 116.2 & 26.2 & & & \\
\hline Rural Girls & 76 & 112.1 & 20.6 & \multirow{2}{*}{10.3} & \multirow{2}{*}{2.81} & \multirow{2}{*}{$3.62 * *$} \\
\hline Urban Girls & 58 & 122.4 & 22.5 & & & \\
\hline Rural Boys & 50 & 115.2 & 21.9 & \multirow{2}{*}{3.32} & \multirow{2}{*}{3.29} & \multirow{2}{*}{$1.00^{\#}$} \\
\hline Rural Girls & 76 & 112.1 & 20.6 & & & \\
\hline Urban boys & 51 & 116.2 & 26.2 & \multirow{2}{*}{5.54} & \multirow{2}{*}{3.77} & \multirow{2}{*}{$1.46^{\#}$} \\
\hline Urban Girls & 58 & 122.4 & 22.5 & & & \\
\hline
\end{tabular}

**Significant at 0.01 level, ${ }^{\#}$ not significant

\section{Analysis}

\subsection{Descriptive Statistics}

Descriptive statistics help us to simply large amounts of data in a sensible way. Each descriptive statistic reduces lots of data into a simpler summary. Here we present our descriptive data (Table 2) in the form of Mean and Standard Deviation (SD) of boys, girls, rural and urban samples.

\subsection{Inferential Statistics}

Inferential statistics plays a pivotal role in hypothesis testing where it is used to determine if a null hypothesis can be rejected or retained. For the present study, we have constructed a two way $(2 \times 2)$ factorial design for the analysis of different variables (Table 3). Table 4 represents the ' $\mathrm{t}$ ' value which is also used to test different null hypotheses.

Table 3. Summary of two way ANOVA results

\begin{tabular}{|c|c|c|c|c|}
\hline Source of variation & SS & df & MS & F ratio \\
\hline A (Residential background) & 2214.31 & 1 & 2214.31 & $7.62^{* *}$ \\
\hline B (Gender) & 44.51 & 1 & 44.51 & $0.15^{\#}$ \\
\hline A $\times$ B & 1288.58 & 1 & 1288.58 & $4.45^{*}$ \\
\hline Within group & 67148 & 231 & 290.68 & \\
\hline **Significan at 0.01 *
\end{tabular}

**Significant at 0.01 level, * Significant at 0.05 level and ${ }^{\#}$ not significant

\section{Results and Discussion}

The data was analyzed to find the answers tothe hypotheses framed for the study. These are presented under various sub heading.

\subsection{Testing of $\mathrm{H}_{1}$}

The ANOVA results reveals that there are statistically significant $(p<0.01)$ differences in emotional intelligence levels of students according to the places they are born and brought up (Table 3). From Table 2 it is observed that the mean scores of emotional intelligence for the students are 113.3 and 119.6 for rural or urban students respectively showing a difference of 6.67 . The calculated ' $\mathrm{t}$ ' value was found to be 2.75 which is higher than that of table value (2.58 at 0.01 level) and thus it is significant at 0.01 level. In the light of the above finding, $\mathrm{H}_{1}$ is rejected.

The emotional climate of the home sets the foundation for almost everything the child does. Feelings of physical safety and emotional security are vitally important for normal development of a child's emotional intelligence. When these are present, children feel free to express themselves and explore their physical, intellectual, and social environments. When these are absent, the child's ability to grow (physically, intellectually, and emotionally) is stifled. So, emotional intelligence highly depends on the characteristics of the places where the students are born and brought up. The differences in home environment between rural and urban sector may leads to higher emotional intelligence. This result corroborates with the findings of Punia and Sangwan (2011) [8], but not with the findings of Gangal and Singh (2012) [11].

\subsection{Testing of $\mathrm{H}_{2}$}

F- value from Table 3 for gender was found to be 0.15 which is not significant at $\mathrm{P}<0.01$. Again ' $\mathrm{t}$ ' value obtained from Table 2 is 0.394 which is also not significant even at 0.05 level. It is clear that the mean of obtained scores (Table 2) for boys (115.7) is negligibly lower than girls (116.6) having a difference of 0.9. In the light of the above finding, $\mathrm{H}_{2}$ is accepted.

Several researches reveal that levels of emotional intelligence vary depending on the sex. It has now become an established truth that female students have a higher 
level of emotional intelligence in comparison to the male students [14,15]. Ahmad et al (2009) [16] concluded that male possesses higher level of emotional intelligence than that of female counter part. Although the previous researches indicate that gender have a significant influence on emotional intelligence, this study has reached a result that does not support that conclusion. This study concludes that gender does not affect the level of emotional intelligence. This finding corroborates with the findings of Lawrence and Deepa (2013) [17], Thilagavathy (2013) [10] and Shree (2013) [18].

\subsection{Testing of $\mathbf{H}_{3}$}

An interaction occurs when the effect of one factor depends on the level of another. If an interaction is significant ( $p$-value <. 05), we conclude that the main effects are not independent of one another and that both effects are important. For this study F- value for the interaction of variables, gender and residential background of the students $(\mathrm{A} \times \mathrm{B})$ was found to be 4.45 (Table 3 ) which is significant at 0.05 level. So, $\mathrm{H}_{3}$ is rejected. So, we have carried out further analysis by applying ' $\mathrm{t}$ ' test (Table 2) for different pairs.

From Table 2 it is clear that out of four pairs only one pair is found to be significant at 0.01 level. The results show that urban girls have higher emotional intelligent than its rural counterpart $(\mathrm{t}=3.62)$. It can be said that urban girls are better in perceiving, identifying, and recognizing emotion. They are better in emotional facilitation of thought and better able to understand emotional facilitation which helps in emotional problem solving. They are also able to handle interpersonal skills and pose a flexible orientation in interpersonal skills and communication.

\section{Conclusion}

This study provides an insight about emotional intelligence and gender differences. Results of the present study demonstrate that there is no significant relationships between emotional intelligence among boys and girls but significant difference exist for rural and urban secondary students at 0.01 level of significant. The samples were classified into four groups i.e. urban boys, urban girls, rural boys, and rural girls. As hypothesized in the present research, urban students have high emotional intelligence when compared with rural students. It means that urban students show more independence assertiveness, self recognition about him/her and management according to the situations than the rural ones. On the other hand, urban girls are found to be more emotionally intelligent that rural girls. So, we can say that they have knowledge about causes of emotions and able to regulate their own emotions. Emotional intelligence is the key for the adjustment of young people lack of which lure of drugs, violent gangs, truancy and dropping out of school may appear. It may give rise to several alarming social problems. So, we can say that rural parents have to create such a home environment so that their children have the opportunity to understand their emotions and to understand and manage the emotions of their peers.

\section{References}

[1] Goleman, D. (1995). Emotional Intelligence: Why it can Matter More than IQ. New York: Bantam Books.

[2] Goleman, D. (1998). Working with Emotional Intelligence, New York: Bantam Books.

[3] Mayer, J. D. and Salovey, P (1990). Emotional Intelligence, Imagination, Cognition and Personality. 9, 185-211.

[4] Goleman, D., Boyatzis, R. E. and McKee, A. (2002). Primal Leadership: Realizing the power of Emotional Intelligence, Harvar Business Press.

[5] Bar-On, R. (2000). Emotional and Social Intelligence: Insights from the Emotional Quotient Inventory. In R. Bar-On, and J.D.A. Parker, (Eds.), The Handbook of Emotional Intelligence 17, pp. 363-388. Jossey-Bass, San Francisco.

[6] Gornefski, G., (2004). Does Emotional Intelligence Predict Unique Variance in Life Satisfaction beyond IQ and Personality? J. Personality and Individual Differences, 38 (4), 1353-64.

[7] Kafetsios, K., (2004). Attachment and Emotional Intelligence Abilities Across the Life Course. Personality and Individual Differences, 37, 129-145.

[8] Punia, S and Sangwan, S (2011). Emotional Intelligence and Social Adaptation of School Children, Journal of Psychology, 2 (2), 83-87.

[9] Chu, J. (2002). Boys Development. Reader's Digest, pp. 94-95.

[10] Thilagavathy, T. (2013). Adjustment and Emotional Intelligence of High School Teachers in Tiruvarur District, International Journal of Teacher Educational Research, 2 (5), 1-6.

[11] Gangal, M.K and Singh, J. (2012). A study of Emotional Intelligence of Teacher Trainee of Meerut City, International Journal of Behavioral, Social and Movement Sciences, 1, 99-106.

[12] Berrocal, P.F, Salovey, P., Vera, A., Extremera, N and Ramos, N. (2005), Cultural Influences on the relation between perceived Emotional Intelligence and Depression, 18 (1), 91-107.

[13] Hair, F.J., Black, C.W., Babin, J.B., Anderson, E. R. and Totham, L.R. (2006). Multivariate Data Analysis. Pearson Printice Hall, Sixth Edition, New Jersey.

[14] Austin E. J., Evans P. G.R. and Potter V. (2005). A Preliminary Study of Emotional Intelligence, Empathy and Exam Performance in First Year Medical Students. Personality and Individual Differences, 39, 1395-1405.

[15] Harrod, N.R. and Scheer, S. D. (2005). An Exploration of Adolescent Emotional Intelligence In Relation to Demographic Characteristics. Adolescence, 40, 159.

[16] Ahmad, S., Bangash, H and Khan, S. A. (2009). Emotional Intelligence and Gender Differences, Sarhad Journal of Agriculture, 25 (1), 127-130.

[17] Lawrence, A.S.A and Deepa, T. (2013). Emotional Intelligence and Academic Achievement of High School Students in Kanyakumari District, International Journal of Physical and Social Science, 3 (2), 101-107.

[18] Shree, R. (2013). The Relationship between Gender and Emotional Intelligence, Indian Journal of Applied Research, 3 (9), 552-553. 